\title{
Marcas del pensamiento de Rousseau en las reflexiones kantianas acerca de las mujeres
}

\section{Carolina Kaufmann \\ UNER-UNR}

\begin{abstract}
Resumen
El presente artículo delimita la impronta de la obra de Jean-Jacques Rousseau en el pensamiento de Immanuel Kant con respecto al modo de ser y de aparecer de las mujeres en el marco de la sociedad moderna e ilustrada. El mismo propone, además de un ejercicio de lectura y recuperación de obras clave de los autores mencionados, una contextualización del pensamiento. Así, con base en los aportes que desde el presente ofrecen autores como Pierre Bourdieu y Françoise Héritier, discute la diferencia entre la mujer y lo femenino, y recupera la historicidad que habita en esta última categoría. De este modo, logra recuperar lo que Kant, siguiendo a Rousseau, pensó para situar a las mujeres en la sociedad moderna. Palabras clave: Mujeres, Kant, Rousseau, educación, Ilustración
\end{abstract}

\begin{abstract}
This article delimits the mark of Jean-Jacques Rousseau's works in Immanuel Kant's thinking regarding women's way of being and appearing within the context of modern, enlightened society. Besides, it proposes an exercise of reading and recuperating key works of the abovementioned authors, a contextualizing of their thinking. So, on the basis of the contributions offered at the present by authors such as Pierre Bourdieu and Françoise Héritier, it discusses the difference between woman and femininity, and recuperates the historicity inhabiting in the last mentioned category. This way it manages to recuperate what Kant, following Rousseau, conceived in order to site women in modern society.

Keywords: Women, Kant, Rousseau, education, Enlightenment
\end{abstract}

KAUFMANN, Carolina, "Marcas del pensamiento de Rousseau en las reflexiones kantianas acerca de las mujeres”, en Avances del Cesor, Año IX, N 9, 2012, pp. 143-162. 


\section{I- Introducción}

Advierten Georges Duby y Michelle Perrot ${ }^{1}$ que las mujeres durante mucho tiempo quedaron abandonadas en la sombra de la historia. ${ }^{2} \mathrm{Y}$ acaso, ¿no quedaron en múltiples oportunidades abandonadas en las sombras de las reflexiones filosóficas? Este trabajo insistirá en una mirada deliberadamente documental respecto del discurso kantiano, surcado por las huellas rousseaunianas, ${ }^{3}$ acerca del papel social asignado a las mujeres. En esta dirección, se pretende profundizar en ciertas argumentaciones autorales aplicadas a la condición de las mujeres, enmarcadas en el tono iluminista y contextual de su época. ${ }^{4}$ De ningún modo

1 DUBY, Georges, PERROT, Michelle, "Presentación”, en Id (directores) Historia de las mujeres. El siglo XIX. Cuerpo, trabajo y modernidad, T. VIII, Taurus, Madrid, 1993.

2 Ibídem. Sobre la vasta bibliografía acerca de la historia de las mujeres como campo de estudio teórico epistemológico, sin pretender agotar el aparato crítico, se sugiere ver: SCOTT, Joan, "Historia de las mujeres", en BURKE, Peter (editor) Formas de hacer historia, Alianza, Madrid, 1991; Id., "El género: una categoría útil para el análisis histórico", en CANGIANO, María Cecilia, DUBOIS, Lindsay (compiladoras) De mujer a género. Teoría, interpretación y práctica feminista en las ciencias sociales, CEAL, Buenos Aires, 1993.

3 En 1962, al cumplirse los 250 años del nacimiento de Rousseau y el $200^{\circ}$ de la publicación del Emilio, se reeditó un ensayo clásico que, entre otros aspectos, señalaría la influencia de Rousseau en las épocas posteriores y en la formación de la conciencia moderna, particularmente las influencias en Kant en los ámbitos éticos, políticos, pedagógicos y en la concepción del principio de autonomía. Nos estamos refiriendo a: MONDOLFO, Rodolfo, Rousseau y la conciencia moderna, EUDEBA, Buenos Aires, 1967. Una lectura desafiante y penetrante de Rousseau en clave contemporánea, puede verse en: TODOROV, Tzvetan, Frágil felicidad. Un ensayo sobre Rousseau, Gedisa, Barcelona, 1987. Formulaciones de Rousseau anticipando las líneas maestras de la solución kantiana, particularmente de los conceptos ético-políticos, pueden verse en HELLER, Agnes, Más allá de la justicia, Planeta Agostini, Barcelona, 1987. Ahora bien, acerca de la lectura kantiana de los escritos de Rousseau, ya sea en el plano de las influencias y/o de las diferencias de ambos filósofos, y efectuada desde diversos ángulos tales como el análisis del estado de naturaleza, de la propiedad privada, del pacto social como fundamento de la sociedad, de sus ideas sociales y del estudio de la libertad y de la voluntad moral, puede verse: GIRALT, María de los Ángeles, "La influencia de Rousseau en el pensamiento de Kant", en Revista de Filosofía de la Universidad de Costa Rica, 1990, XXVIII (67/68), pp. 119-127. Lamanna destaca las coincidencias y divergencias en las ideas pedagógicas kantianas y rousseaunianas (LAMANNA, Paolo, Historia de la Filosofía, De Descartes a Kant, T. III, Hachette, Buenos Aires, 1964). En cuanto a Lerena disecciona en profundidad las contradicciones del pensamiento ilustrado en las "Sombras del Siglo de las Luces", "Rousseau, o la otra cara de Prometeo", sin excluir a Kant cuyo "consejero pedagógico era Rousseau.", destacando -en múltiples oportunidades- la adhesión y deuda hacia el ginebrino en el filósofo alemán (LERENA, Carlos, Reprimir y liberar. Crítica sociológica de la educación y de la cultura contemporánea, Akal, Madrid, 1983).

4 En este aspecto, remitimos a la obra de Ernst Cassirer, historiador de las ideas que destaca el ascendiente rousseauniano sobre Kant (CASSIRER, Ernst, Rousseau, Kant, Goethe. Filosofía y cultura 
aspiramos a plantear el problema de la verosimilitud antropológica ni sociológica sino, al decir de Jean Braudillard, ${ }^{5}$ a ubicarnos en la posición del viajero imaginario que tropieza con esos escritos que nos ilustran en la novela de lo femenino dieciochesco en la tradición europea. Finalmente, recorreremos un tramo analítico acompañados por las miradas contemporáneas de una reconocida antropóloga y de un provocador sociólogo.

Bonnie Anderson y Judith Zinsser ${ }^{6}$ sostienen con respecto a las mujeres que tanto en el Renacimiento como en la Revolución Científica "las metas y los ideales de estos movimientos se concebían como algo exclusivamente aplicable a los hombres, tampoco hubo Ilustración para las mujeres". Más adelante, agregan: "continuaban reafirmando las más antiguas tradiciones heredadas acerca de las mujeres: que éstas eran inferiores a los hombres en las facultades cruciales de la razón y la ética y, por tanto, debían estar subordinadas a los hombres. En la filosofía y el arte, los hombres de la Ilustración mantenían el antiguo ideal de mujer: callada, obediente, sumisa, modesta y casta". ${ }^{7}$ Si bien a partir de 1760, el problema de la educación femenina y masculina invade las conciencias ilustradas, ${ }^{8}$ la glorificación de la domesticidad y virtudes femeninas y de la educación doméstica familiarista ${ }^{9}$ puede ser leída no sólo en los autores dieciochescos sino en producciones anteriores. ${ }^{10}$

Llegados a este punto, nos replegamos a interrogantes no exclusivos del repertorio de las Luces que irán deshojando nuestras inquietudes, tales como ¿Cuáles son los términos o mensajes para referirse a la condición de lo femenino? ¿Qué se piensa y espera de la posición de las mujeres socialmente? ¿Qué requisitos, cualidades, atributos deben cumplimentar las mujeres para ser aceptadas y valoradas más allá de la escena doméstica? ¿Qué valores se instituyen socialmente para conservar o modificar el lugar otorgado a las mujeres por la sociedad? ¿Qué patrones educativos se proponen en su educación? ¿Qué cristalización de significaciones operan como organizadores de sentido gestando determinadas prácticas sociales? ¿Cómo debían orientarse las actividades femeniles fuera del espacio privado? Obviamente, responder algunos de estos interrogantes -entre otros muchos posibles- sólo cobra sentido si se los ubica enmarcados en un proceso multideterminado por los factores

en la Europa del siglo de las Luces, Fondo de Cultura Económica, España, 2007).

5 BRAUDILLARD, Jean, El otro por sí mismo, Anagrama, Barcelona, 1988.

6 ANDERSON, Bonnie, ZINSSER, Judith, Historia de las mujeres: una historia propia, V. III, Crítica, Barcelona, 1992, p. 135.

7 Ídem, p. 136.

8 SONNET, Martine, "La educación de una joven", en DUBY, Georges y PERROT, Michelle, Historia de las mujeres. Del Renacimiento a la Edad Moderna, T.VIII, Taurus, Madrid, 1992.

9 LERENA, Carlos, Reprimir y liberar..., Op. Cit.

10 KAUFMANN, Carolina, "Pedagogía de los comportamientos", en Id. (directora) Ahorran, acunan y martillan. Marcas de urbanidad en los escenarios educativos argentinos (primera mitad siglo XX), EDUNER (Editorial de la Universidad Nacional de Entre Ríos), Paraná, 2012. 
económicos, políticos, socioculturales e ideológicos. Entre estos últimos, se inscribe el sistema de creencias, representaciones, valores, ideas y opiniones que configuran los integrantes de una sociedad para establecer cierto orden en sus intercambios o interrelaciones, conocido este proceso como subjetividad social, constituyente de la vida social. ${ }^{11}$ Resulta obvio mencionar que el discurso normativo sobre las mujeres conlleva el análisis de las relaciones entre los sexos. En este sentido, las miradas de Françoise Héritier y de Pierre Bourdieu asistirán nuestro recorrido en el repaso de las condiciones históricas de producción de subjetividad femenina.

Con estas precisiones, en principio, direccionaremos nuestra revisión hacia las Observaciones sobre el sentimiento de lo bello y lo sublime, título con el que Kant publicó en 1764 sus Observaciones, dos años después de ver la luz el Emilio de Rousseau. Precisamente, en este ensayo se ocupará por primera vez del problema estético, posteriormente retomado en su Crítica del Juicio. Mas no se priva de explicitar que su propósito radica en "analizar sentimientos"; sus observaciones, hechas "más con el ojo de un observador que de un filósofo", ${ }^{12}$ sientan precedentes en la construcción/deconstrucción de ciertas subjetividades contemporáneas.

¿Y por qué comenzar a centrar nuestra mirada en este breve ensayo? Por múltiples motivos. En principio, porque este trabajo se inscribe en consonancia con el proyecto ${ }^{13}$ que aborda uno de los núcleos problemáticos debatidos en la filosofía contemporánea: la cuestión del sujeto y sus proyecciones en diferentes campos, particularmente en el campo educativo. Al mismo tiempo, porque nos posibilita continuar profundizando en problemáticas que hemos investigado en los últimos años vinculadas con las lecturas de urbanidad en los contextos pedagógicos. ${ }^{14}$ En términos amplios, estas temáticas y proble-

11 En este trabajo no nos detendremos en las discusiones que giran en torno a la naturaleza de la mujer, tal es el caso de Mary Wollstonecraft y Germaine de Staèl quienes rebaten los puntos de vista rousseaunianos. KAPPELLI, Anne Marie, "Escenarios del feminismo", en DUBY, Georges, PERROT, Michelle (directores) Historia de las mujeres. El siglo XIX. Cuerpo, trabajo y modernidad, T. VIII, Taurus, Madrid, 1993.

12 KANT, Immanuel, Lo bello y lo sublime. La paz perpetua, Espasa-Calpe, Madrid, 3ra edición, 1957, p. 11. Se han realizado numerosas ediciones sueltas de las Observaciones sobre el sentimiento de lo bello y lo sublime; en nuestro caso remitimos a la versión mencionada.

13 Miembro del equipo de investigación del Proyecto Unidad y conflicto. La cuestión de la subjetividad en las lecturas contemporáneas de Kant. Dirección Pilar Britos, Co-Dirección María Elena Candioti, Facultad de Ciencias de la Educación, Universidad Nacional de Entre Ríos (2009-2012). Presentación del Informe Final: marzo 2012.

14 Esas lecturas e investigaciones se concretaron en el Proyecto de Investigación bajo mi dirección: Textos escolares. Manuales de urbanidad argentinos (primera mitad del siglo XX). Facultad de Ciencias de la Educación, Universidad Nacional de Entre Ríos (2004-2009). Producto de ese proyecto, se encuentra en prensa: KAUFMANN, Carolina (directora) Ahorran, acunan y martillan..., Op. Cit.

\section{6}


máticas ${ }^{15}$ del orden de la sociabilidad, la cortesía, la limpieza, la modestia, se constituyen en categorías vitales del universo subjetivo, categorías que horadarán en la constitución de los sujetos y que los filósofos aludidos retomarán en sus trabajos. Por añadidura a lo ya dicho, nos motiva el abordaje de este tópico puesto que desde lo personal ${ }^{16}$ nos involucra en la investigación de una faceta que no hemos visto suficientemente explorada en el vastísimo corpus teórico kantiano, ${ }^{17}$ ni particularmente en trabajos marcados por la traza pedagógica, ${ }^{18}$ ni en reflexiones críticas acerca de Kant. ${ }^{19}$

Consideramos que las problemáticas sobre las urbanidades escolarizadas han marcado derroteros educativos no sólo europeos sino también latinoamericanos, y específicamente argentinos, a partir de fines del siglo XIX y primera mitad del siglo XX. Por otra parte, los resabios de las urbanidades estudiados han sido deudores de concepciones de largo aliento en la historiografía educativa post renacentista y se fueron aggiornando a los diferentes aires iluministas y post iluministas. Estas lecturas no dejan fuera los manifiestos pro urbanidad que atesorarán no sólo las instituciones educativas sino también los textos escolares y las prácticas educativas.

15 ELIAS, Norbert, El proceso de la civilización. Investigaciones sociogenéticas y psicogenéticas, Fondo de Cultura Económica, México, 2011.

16 Ver: KAUFMANN, Carolina (directora) Ahorran, acunan y martillan..., Op. Cit.

17 No resulta oportuno reseñar acá el monumental corpus kantiano de mayor influencia en la modernidad y que abarca áreas cognitivas de envergadura: obras filosóficas, epistemológicas, ética; estéticas, políticas, filosofía crítica, teología, filosofía de la religión; pedagógicas, son deudoras de la obra kantiana. Igualmente, investigaciones y trabajos acerca de sus obras realizadas por sus críticos, comentaristas, detractores y continuadoras, se han multiplicado exponencialmente a partir del siglo XVIII en elencos bibliográficos relevantes. En función de nuestro trabajo y de las miradas contemporáneas de Kant, sin ánimo de ser exhaustivos, remitimos a algunos de los textos relevantes que dan cuenta de la proyección kantiana en clave actual y que constituyen insumos bibliográficos de nuestro proyecto de investigación, a saber: GÓMEZ CAFFARENA, José, Estudio preliminar acerca de I. Kant. La contienda entre las facultades de filosofia y teología, Editorial Trotta, Madrid, 1999; FUNKE, Gerhard, "Volver a Kant significa avanzar", en Anales del Seminario de Historia de la Filosofía, $\mathrm{N}^{\circ}$ 9, 13-37, Editorial Complutense, Madrid, 1992; KANZ, Heinrich, "Immanuel Kant (1724-1804)", en Perspectivas, Unesco, XXIII, N. 3-4, 1993, pp.837-854; CASTRO, Edgardo, "Foucault, lector de Kant", en FOUCAULT, Michel, Una lectura de Kant. Introducción a la antropología en sentido pragmático, Siglo XXI, Buenos Aires, 2009; VANDEWALLE, Bernard, Kant. Educación y crítica, Ediciones Nueva Visión, Buenos Aires, 2001; ROSALES, Alberto, Ser y subjetividad en Kant. Sobre el origen subjetivo de las categorías, Biblos, Buenos Aires, 2009.

18 Desde sus lecciones universitarias de pedagogía ya en Könisberg, a la publicación de su tratado de Pedagogía, han mediado interesantes reflexiones acerca del universo pedagógico kantiano, enmarcado en el tempus ilustrado.

19 Exceptuamos el "Estudio Preliminar" a las Observaciones realizado por la Directora del Centro de Documentación Kantiana de la Universidad Autónoma Metropolitana de México, Dulce María Granja de Castro en el Estudio Preliminar a la edición crítica bilingüe de: KANT, Immanuel, Observaciones 
Además, y sin pretender esquematizar ni reducir el discurso educativo acerca de las mujeres, nos interesa interpelar la perspectiva kantiana en cuanto a las disimilitudes que establece entre los sexos y cómo estas diferencias operarían en el marco de la enseñanza. Esas disparidades anticipadas repercutían lejanas a posturas igualitarias remitiendo a diferencias naturalizadas, siempre destacando que la educación para las mujeres y los varones debía perseguir todo esfuerzo por fomentar la perfección moral. A tales efectos, resulta interesante la revisión de la Antropología ${ }^{20}$ kantiana, respecto de las individualizaciones realizadas en torno al "carácter del sexo".

\section{II. "Las nobles cualidades del bello sexo" o las urbanidades ilustradas}

Si bien el discurso ilustrado es un discurso del hombre, ${ }^{21}$ dirigido a todos los hombres en cuanto género humano o de la especie bípeda, racional que sólo puede darse en la dimensión de lo universal, ${ }^{22}$ nos detendremos en el discurso cuando específicamente está direccionado a la "mitad femenina".

Ciertamente, en pos del progreso de las Luces, múltiples caracterizaciones y conceptualizaciones acerca de las mujeres son ofrecidas por Rousseau ${ }^{23}$ en el Libro Quinto del Emilio (publicado en 1762) marcando las diferencias y afinidades entre ambos sexos "con el fin de ocupar el puesto adecuado en el orden físico y moral". En este sentido y sin intención de agotar esta esfera, menciono algunas precisiones efectuadas por Rousseau respecto de las mujeres: "importa que sea modesta, recatada, atenta"; 24 "Deben aprender muchas cosas,

sobre el sentimiento de lo bello y lo sublime, FCE, México, 2004.

20 La Antropología Filosófica en sentido pragmático fue publicada en 1797 coincidiendo con el final de los cursos y el retiro definitivo de Kant como profesor (KANT, Immanuel, Antropología en sentido pragmático, Alianza Editorial, Madrid, 2004). Sobre la Antropología, ver FOUCAULT, Michel, Una lectura de Kant. Introducción a la Antropología en sentido pragmático, Siglo XXI, Buenos Aires, 2009.

21 Con relación a las mujeres en la filosofía ilustrada francesa, Catherine Larrière destaca que las mujeres no participaron de la Ilustración (Id., "¿Sexo o rango? La condición de las mujeres en la filosofía de la Ilustración", en FAURÉ, Christine (directora) Enciclopédica histórica y política de las mujeres. Europa y América, Akal, Madrid, 2010).

22 CRAMPE-CASNABET, Michelle, "Las mujeres en las obras filosóficas del siglo XVIII", en DUBY, Georges, PERROT, Michelle (directores) Historia de las mujeres. Del Renacimiento a la Edad Moderna, T.VIII, Taurus, Madrid, 1992.

23 En Julia o la Nueva Eloísa, publicada un año antes del Emilio, Julia lleva al extremo el lugar del modelo ideal de mujer rousseauniana y el lugar del encargado o la encargada, de la educación negativa. Además de que la delicia de Julia consiste en ser la Eloísa medieval recuperada en clave moderna. ROUSSEAU, Jean-Jacques, Julia o la nueva Eloísa, Akal, Madrid, 2007.

24 ROUSSEAU, Jean-Jacques, Emilio o De la Educación, Bruguera, Barcelona, 1983, p. 505.

\section{8}


pero sólo las que es conveniente que sepan",25 "La blandura es la prenda primera y más importante de una mujer; destinada a obedecer al hombre...". ${ }^{26}$ Engarzadas en su trama analítica, condiciones tales como el decoro, la castidad, la honra, la reputación, el pudor, el recato, ${ }^{27}$ la obediencia, la modestia, la prudencia, la honestidad, la amabilidad, la sujeción, la sumisión permean el discurso rousseauniano acerca de la "naturaleza" y virtudes propias de las mujeres. Sin duda, la teoría rousseauniana ensalzaba la caracterización de la maternidad ${ }^{28}$ como pilar básico femenino.

Con referencia a las niñas, señala variadas "inclinaciones de su sexo" y "vicios propios de las mujeres", como la astucia, la inconstancia, los caprichos y las manías. Además:

Los dos defectos más peligrosos para ellas, y de los cuales es muy difícil que se desprendan una vez que los han contraído, son la ociosidad y la indocilidad. Las doncellas deben ser laboriosas, pero no basta con esto; desde muy pequeñas deben estar sujetas. ${ }^{29}$

En cuanto a la cultura conveniente para las mujeres, Rousseau aspira al logro de "conocimientos agradables" y en este sentido argumenta:

La investigación de las verdades abstractas y especulativas, de los principios y axiomas en las ciencias, todo lo que tiende a generalizar las ideas, no es propio de las mujeres; sus estudios se deben referir a la práctica, y les toca a ellas aplicar los principios hallados por el hombre y hacer las observaciones que le conducen a sentar principios. ${ }^{30}$

A las mujeres compete hallar, por decirlo así, la moral experimental, y a nosotros reducirla a sistema. ${ }^{31}$

En síntesis, Martine Sonnet corona su lectura acerca del rol social que les cabe a las mujeres a través de palabras del Jean-Jacques: "La mujer nunca accede al saber por sí misma, sino para hacer agradable su presencia a quienes la rodean. No cabe duda de que no está hecha para la ciencia, sino para agrado y para bienestar de su esposo e hijos". ${ }^{32}$

25 Ídem, p. 508.

26 Ídem, p. 516.

27 Jean-Marie Goulemot señala que el debate pedagógico tan importante durante la Ilustración no eludía el problema del pudor y del recato, problemas aparecidos en el Emilio. Ver: "Las prácticas literarias o la publicidad de lo privado", en ARIĖS, Philippe, DUBY, Georges (directores) Historia de la vida privada. El proceso de cambio en la sociedad de los siglos XVI-XVIII, T. V, Taurus, Madrid, 1992.

28 ANDERSON, Bonnie, ZINSSER, Judith, Historia de las..., Op. Cit.

29 ROUSSEAU, Jean-Jacques, Emilio o..., Op. Cit., p. 515.

30 Ídem, p. 538.

31 Ibídem.

32 SONNET, Martine, "La educación de una...", Op. Cit., p. 137. 
Ahora bien, previamente a centrarnos en el análisis kantiano acerca de algunas de las cualidades de las mujeres, a título ilustrativo, sólo citamos unos renglones de Kuno Fisher, otrora rector de la Universidad de Heidelberg, quien dibuja algunos perfiles de las particularidades de la vida del filósofo y adelanta ciertos trazos con respecto a la postura kantiana acerca del universo femenino:

...No debe por esto creerse que fuera insensible o contrario a las mujeres, porque no era ni lo uno ni lo otro, antes bien, gustaba en extremo de su trato y dícese que se mostraba con ellas sumamente amable y atento. Eso sí, no habían de ser eruditas, ni debía versar la conversación sobre puntos que traspasaran los límites prescriptos de la buena sociedad. Le impresionaban vivamente las gracias y los encantos que da a la sociedad la mujer, pero también es verdad que no sintió mucho que le fuera indispensable en su vida íntima esta bella mitad del género humano. ${ }^{33}$

Entonces, atendamos a las categorías perceptivas que Kant propone al referirse a las "nobles cualidades del bello sexo": 34

Para alejarse todo lo posible de lo repugnante conviene la limpieza, que sienta bien en toda persona. En el sexo bello pertenece a las virtudes de primera fila y difícilmente puede ser exagerada, mientras en el hombre rebasa a veces la medida y resulta pueril..$^{35}$

El pudor es un secreto de la naturaleza para poner barrera a una inclinación muy rebelde y que contando con la voz de la naturaleza parece conciliarse siempre con cualidades buenas morales, aun cuando incurra en excesos. ${ }^{36}$... Esta cualidad es principalmente propia del bello sexo, y le sienta muy bien. ${ }^{37}$

Si bien Kant otorga prioridad a lo bello entre todas las cualidades del sexo femenino, también destaca "...la modestia, una especie de noble sencillez e ingenuidad recubriendo notables condiciones". 38

33 FISHER, Kuno, "Vida de Kant e historia de los orígenes de la filosofía crítica", en KANT, Immanuel, Crítica de la Razón Pura. I Estética Trascendental y Analítica Trascendental, Losada, Buenos Aires, 1973, p. 68.

34 Norbert Elias destaca que en el caso específico alemán y remontándonos a épocas previas al 1500, "Las mujeres públicas o como se las solía llamar en Alemania, las "mujeres bellas", las "bonitas", constituyen una corporación con derechos y deberes determinados dentro de la ciudad al igual que cualquier otra profesión", connotación diferente a la brindada por Kant siglos después. ELIAS, Norbert, El proceso de la..., Op. Cit., p. 267.

35 KANT, Immanuel, Lo bello y lo sublime......, Op. Cit., p. 51 (cursiva en el original).

36 Ibídem.

37 Ídem, p. 52.

38 Ídem, p. 53 (cursiva en el original). 
Sólo es de desear que el falso brillo, tan fácilmente engañador, no nos aleje de un modo insensible de la noble sencillez y, sobre todo, que el secreto, aún oculto, de la educación consiga ser sustraído a los antiguos errores para elevar temprano el sentimiento moral en el pecho de todo joven ciudadano a una sensibilidad activa... ${ }^{39}$

El trato social y los procederes públicos que se imponían durante los años de las Luces aún debían desarrollarse dentro de las más estrictas normas de modestia, moral y buenas maneras. Es decir, los excesos de lujos, ostentación y actitudes llamativas quedaban proscritos. Para inculcar estas ideas a las mujeres, no faltaron prácticas normativas tendientes a consolidar los mandatos morales.

Pero no todas son virtudes en el bello sexo, el filósofo también refiere a los defectos/ Virtudes negativas que arrojan luz sobre el núcleo de intersección de los pensamientos kantianos acerca de las mujeres:

La vanidad que se suele reprochar al bello sexo, si es que en él resulta un defecto, es un bello defecto. ${ }^{40}$

Si la vanidad es defecto que en una mujer bien merece disculpa, el engreimiento en ellas no es sólo censurable, como en toda persona en general, sino que desfigura completamente el carácter del sexo. ${ }^{41}$

Ha de distinguirse siempre la vanidad y el engreimiento. La primera solicita el aplauso y honra en cierto modo a aquellos por los cuales se toma este trabajo; el segundo se cree en completa posesión de él y, no esforzándose en conseguirlo, no logra obtenerlo. ${ }^{42}$

\section{Lo bello y lo sublime en tono kantiano}

Natalie Zemon Davis menciona la importancia de comprender el significado de los se$x o s$, de los grupos genéricos en el pasado histórico, resaltando la importancia en descubrir los distintos niveles de los roles sexuales y de los simbolismos sexuales en las diferentes sociedades y períodos para comprender el sentido que han tenido y los modos de funcionamiento en virtud de mantener el orden social o para promover el cambio. ${ }^{43}$

Con el foco puesto en los roles destinados a cumplir por las mujeres, volvemos a Kant quien ya en el capítulo III, "Sobre la diferencia entre lo sublime y lo bello en la relación recíproca entre ambos sexos", reafirma la exactitud de nominar a la mujer como depositaria

39 Ídem, pp. 83-84.

40 Ídem, p. 49 (cursiva en el original).

41 Ídem, pp. 49-50.

42 Ídem, p. 50.

43 ZEMON DAVIS, Natalie, "Women`s History in Transition: the European Case", Feminist Studies, $\mathrm{N}^{\circ} 3$, invierno de 1975-1976. 
del bello sexo particularizando sus rasgos distintivos. Es el carácter de lo bello el centro de las cualidades en las mujeres y lo sublime, característica masculina. De hecho, comparativamente esta belleza ${ }^{44}$ esconde en el planteo kantiano viscerales incompatibilidades: "El bello sexo tiene tanta inteligencia como el masculino, pero es una inteligencia bella; la nuestra ha de ser una inteligencia profunda, expresión de significado equivalente a lo sublime". ${ }^{45}$ Virtud bella/virtud noble ${ }^{46}$, la primera adorna a las mujeres en sus cualidades intrínsecas según el filósofo; la segunda caracteriza a los hombres.

Luego, en la Antropología ${ }^{47}$ Kant señala que "Las cosas propias de la mujer llámanse debilidades" ${ }^{48}$ marcando que en el estado de naturaleza la mujer es "un animal doméstico". ${ }^{49}$ En cuanto a las observaciones sueltas realizadas en torno a las mujeres y sus consecuencias pragmáticas, Kant destaca las cualidades femeninas en contraposición a las masculinas:

La mujer debe ser paciente, el varón tiene que ser tolerante. Aquélla es sensible, éste sensitivo. La economía del varón consiste en ganar, la de la mujer en ahorrar. El varón es celoso cuando ama, La mujer lo es aún sin amar... ${ }^{50}$

Consecuencias de estas características conducen a que "El sexo femenino tiene que educarse y disciplinarse a sí mismo en el orden práctico; el masculino no sabe hacerlo".51

¿Y qué rol le cabe a la educación en esta dicotomía analítica? Escuchemos a quien en otras arenas, con pretensiones universalistas ilustradas, clamaba iiSapere aude!! Aquel cuya educación ilustrada ${ }^{52}$ no podía soslayar en el marco varonil el doble aprendizaje del pensamiento y la libertad como desiderátum impostergable:

44 Con relación a la estética corporal y a la entidad femenina manifestada a través de la belleza, Cfr. NAHOUM GRAPPE, Veronique, “La estética ¿máscara táctica, estratégica o identidad petrificada?”, en FARGE, Arlette, ZEMON DAVIS, Natalie (directoras) Historia de las mujeres. Del Renacimiento a la Modernidad, T. III, Taurus, Madrid, 1992.

45 KANT, Immanuel, Lo bello y lo sublime..., Op. Cit., p. 45 (cursiva en el original).

46 Ídem, p. 48.

47 Acerca de la génesis de la Antropología, de su inserción en el pensamiento kantiano, su estructura y especificidad, FOUCAULT, Michel, Una lectura de..., Op. Cit.

48 KANT, Immanuel, Antropología en sentido pragmático..., Op. Cit., p. 244 (traducción textual).

49 Ídem, p. 255.

50 Ídem, p. 249 (cursiva en el original).

51 Ídem, p. 250. En este sentido, Norbert Elias señala las obligaciones de autodisciplina y autoeducación que corresponden a la sociedad cortesano-absolutista del siglo XVIII en función de las nuevas situaciones sociales que recaen sobre los sexos. Id., El proceso de la..., Op. Cit.

52 LAMANNA, Paolo, Historia de la..., Op. Cit. (T. VI - El problema pedagógico-educativo: "Las ideas pedagógicas de Kant"). 
La meditación profunda y el examen prolongado son nobles, pero pesados, y no sientan bien a una persona en la cual los espontáneos hechizos deben sólo mostrar una naturaleza bella. El estudio trabajoso y la reflexión penosa, aunque una mujer fuese lejos en ello, borran los méritos peculiares de su sexo... ${ }^{53}$

Más adelante, Kant prescribe:

El estudio trabajoso y la reflexión penosa, aunque una mujer fuese lejos en ello, borran los méritos peculiares de su sexo, y si bien la rareza de estas condiciones en su sexo las convierte en objeto de fría admiración, debilitan al mismo tiempo los encantos que les otorgan su fuerte imperio sobre el sexo opuesto. A una mujer con la cabeza llena de griego, como la señora Dacier, o que sostiene sobre mecánica discusiones fundamentales, como la marquesa de Chatelet, parece que no le hace falta más que una buena barba... 54

La mujer, por tanto, no debe aprender ninguna geometría; del principio de razón suficiente o de las mónadas sólo sabrá lo indispensable para entender el chiste en las poesías humorísticas con que se ha satirizado a los superficiales sutilizadores de nuestro sexo. ${ }^{55}$

En historia no se llenarán la cabeza con batallas ni en geografía con fortalezas; tan mal sienta en ellas el olor de la pólvora como en los hombres el del almizcle. ${ }^{56}$

La figura delicada, la ingenuidad alegre y el afecto encantador le indemnizan suficientemente de la falta de erudición libresca y de otras faltas que con su talento pueda suplir. ${ }^{57}$

Detrás de estas objeciones subyacían, cuando menos, dos razones. Una de ellas, la marcada inclinación a limitar los contenidos a ser enseñados y aprendidos por las mujeres. En segundo lugar, no descuidar y fortalecer la educación moral ${ }^{58}$ satisfaciendo así las necesidades del ceremonial masculino. ${ }^{59}$ En esta dirección, sin detenernos en lo dicho en cuanto

53 KANT, Immanuel, Lo bello y lo sublime..., Op. Cit., p. 45.

54 Ibídem.

55 Ídem, p. 46.

56 Ibídem.

57 Ídem, p. 61.

58 Si bien la exposición pedagógica de la moral en tono kantiano tiene relación con la interioridad de los sentimientos humanos, la moralidad es un término típicamente kantiano que describe un fenómeno complejo no sólo normativo sino, en parte, antropológico y también teológico. Pues bien, la moralidad no se refiere primariamente a la corrección o incorrección de una acción según el criterio universal determinado por el imperativo categórico, sí a los motivos e impulsos que llevan a los sujetos a realizar una acción cuya corrección se da por descontada.

59 Bernard Vandewalle, en su lectura de Kant, destaca que la educación moral no consiste en con- 
a la sensibilidad en términos antropológicos,${ }^{60}$ volvemos a lo expresado por el filósofo en relación con el rol de los conocimientos y de las facultades de conocer propias de las mujeres:

Su filosofía no consiste en razonamientos, sino en la sensibilidad. ${ }^{61}$

Se procurará ampliar todo su sentimiento moral y no su memoria, valiéndose del juicio personal sobre los actos que ven en torno suyo. ${ }^{62}$

Efectivamente, esas características que exaltan los sentimientos interiores sobre la razón, la reivindicación de la interioridad, el responder a las exigencias morales del sentimiento, deudoras todas del vigor del discurso rousseauniano (ver "Profesión de fe" en el Emilio), ${ }^{63}$ calan en el discurso iluminista que Rousseau "supo enseñar", en palabras de Mondolfo.

\section{Lecciones kantianas}

En sus Cartas sobre el progreso de la humanidad, Herder retrata ciertas particularidades de su pretérito maestro vinculadas a las lecciones y a las fuentes que utilizaba el filósofo para amenizar sus clases:

Con el mismo interés examinaba a Leibniz, Wolff, Baumgarten, Crusius, Hume; estudiaba las leyes de la Naturaleza, de Kepler y otros físicos; daba entrada a los escritos de Rousseau, Emilio y la Eloísa, que entonces acababan de publicarse. ${ }^{64}$

Más allá de la certeza del uso de las fuentes rousseaunianas por parte de Kant, ${ }^{65}$ resulta evidente la similitud en el enfoque, tratamiento y conceptualización de las mujeres que brindan tanto Kant como Rousseau. Por esto, sería inadmisible descontextualizarlos de los mandatos ideológicos de su época, signados por el humanismo europeo de las Luces.

mover el corazón de los niños y subraya que el filósofo procura favorecer un ejercicio despegado de la sensibilidad patológica, siendo que la sensiblería enturbia la lucidez de la razón. VANDEWALLE, Bernard, Kant. Educación..., Op. Cit.

60 KANT, Immanuel, Antropología..., Op. Cit., pp. 43-85

61 KANT, Immanuel, Lo bello y lo sublime..., Op. Cit., p. 47

62 Ibídem.

63 "el subjetivismo anterior a Rousseau tiene un carácter marcadamente intelectualista: se prende del pensamiento, hace el análisis del intelecto, se concentra sobre todo en el problema del conocimiento. Con Rousseau aparece una afirmación diferente del sujeto: se proclama la superioridad del sentimiento sobre la razón; se penetra resueltamente en el mundo moral", en MONDOLFO, Rodolfo, Rousseau y la.., Op. Cit., p. 30.

64 Herder's Werke, Philosophie und Geschiste, Bd XIV en FISHER, Kuno, "Vida de Kant...”, Op. Cit., p. 40.

65 CASSIRER, Ernst, Rousseau, Kant..., Op. Cit.

\section{4}


En otro orden de cosas, destacamos que años después de la publicación de las Observaciones Kant expone: "he dado durante unos treinta años dos cursos referentes al conocimiento del mundo: Antropología (en el semestre de invierno) y Geografía física (en el de verano), a los cuales, como lecciones populares, encontraron oportuno asistir también otra clase de público". ${ }^{66}$

En cualquier caso, Kant otorgó una importancia vital a la enseñanza y al aprendizaje de la geografía, ${ }^{67}$ particularmente preguntándose ¿qué debería interesar a las mujeres acerca de la enseñanza de la geografía?

En este punto, es sabido que Kant concede valor al cultivo de los sentidos, la mirada y la imaginación recibiendo la colaboración de disciplinas prácticas que las estimulan, por caso, la geografía que tiene la ventaja de estimularla y dominarla mediante figuras precisas. ${ }^{68}$ Pero, ¿es la misma geografía a la que deben acceder los niños y las niñas? ¿Cumple las mismas finalidades su aprendizaje-enseñanza? ¿Qué normas educativas regulan/deberían regular la apropiación de los aprendizajes? Escuchemos a Kant:

Es bello que se haga agradable a una mujer la vista de un mapa donde se representa toda la tierra o la porción más importante de ella. Esto se obtiene presentándola sólo con el propósito de describir los diversos caracteres de los pueblos que la habitan, sus diferencias en el gusto y en el sentimiento moral, principalmente con respecto al influjo que tienen éstas en las relaciones de ambos sexos, explicando todo ellos ligeramente por el diferente clima, la libertad o la esclavitud. Poco importa que sepan o no las particulares divisiones de estos países, su industria, su poderío o sus soberanos. Del universo, igualmente, sólo es menester que conozcan lo necesario para hacerles conmovedor el espectáculo del cielo en una hermosa noche, cuando han comprendido en cierto modo que existen otros mundos y en ellos también hermosas criaturas. ${ }^{69}$

Respecto de la experiencia estética y la enseñanza de las bellas artes Vandewalle, citando a Kant, reflexiona: "el maestro no impone las reglas o límites de sus propias producciones: estimula la imaginación de su alumno para que éste cree las reglas de su propia producción". ${ }^{70}$ En este sentido, Kant, sin perder de vista el sendero pedagógico que marca para las mujeres, caracteriza las notas esenciales que debe cumplimentar la enseñanza artística ligada a las condiciones específicas de su sexo:

66 KANT, Immanuel, Antropología..., Op. Cit., p. 21. Según Foucault, Kant había iniciado su enseñanza de la geografía en 1756 y los cursos de Antropología datan de un período posterior (FOUCAULT, Michel, Una lectura de Kant..., Op. Cit., p. 135).

67 KANT, Immanuel, Bosquejo y anuncio de un curso de geografía física, s/d, 1757.

68 KANT, Immanuel, Propos de pédagogie, V. 3, p. 1182 citado en VANDEWALLE, Bernard, Kant. Educación..., Op. Cit.

69 KANT, Immanuel, Lo bello y lo sublime..., Op. Cit., pp. 47-48.

70 VANDEWALLE, Bernard, Kant. Educación..., Op. Cit., p. 28. 
El sentimiento para las pinturas y para la música, no como arte, sino como expresión de la sensibilidad, afina o eleva el gusto de este sexo y tiene siempre algún enlace con los movimientos morales. Nunca una enseñanza fría y especulativa, siempre sensaciones, y éstas permaneciendo tan cerca como sea posible de sus condiciones de sexo. Semejante instrucción es tan rara porque exige aptitudes, experiencia y un corazón lleno de sentimiento. De toda otra puede la mujer muy bien prescindir, y aun sin ésta se afina comúnmente muy bien por sí misma. ${ }^{71}$

Peculiarmente en el contexto general kantiano, las pautas y regulaciones emotivas hacia la educación artística brindadas a las niñas y que emanan de sus afirmaciones remiten a divisiones crecientes acerca de las pautas socio-cognitivas propias y exclusivas de los diferentes sexos.

\section{Miradas contemporáneas acerca la dominación masculina Kant revisitado}

Iniciamos este párrafo motivadas por los hilos y el entramado central del proyecto ${ }^{72}$ relacionado con la cuestión de la subjetividad y cómo ésta requiere asumir la tensión entre la unidad del sujeto y el conflicto de facultades e instancias involucradas. Con este horizonte en la mira comenzamos este tramo, revisando las reflexiones de la antropóloga Françoise Héritier $^{73}$ quien en el Tomo I de Masculino/Femenino. El pensamiento de la diferencia ${ }^{74}$, texto en el que, apoyándose en investigaciones etnológicas, muestra cómo se constituyen las categorías iniciales del pensamiento basadas en la oposición de lo idéntico y diferente, partiendo de la observación de las regularidades anatómicas y fisiológicas.

La misma autora, luego, en el Tomo II de Masculino/Femenino. Disolver la jerarquía, avanza sobre el pensamiento de la diferencia, “...es decir, sobre la manera en que la diferencia entre los sexos, que no implica absolutamente ninguna jerarquía, ha sido pensada en las diversas sociedades del mundo desde los comienzos de los tiempos". ${ }^{75} \mathrm{Si}$ bien la diferenciación anatómica y sexuada establece una constatación, en esta diferencia sexuada la voluntad no reviste ninguna influencia y, por otro lado, condiciona la aparición de categorías binarias jerarquizadas, "sexo fuerte"/“sexo débil".

71 KANT, Immanuel, Lo bello y lo sublime..., Op. Cit., pp. 47-48

72 Ver cita 13.

73 "El predominio de los hombres no tiene ningún fundamento", entrevista publicada a Françoise HÉRITIER realizada por Luisa CORRADINI, en La Nación, 09/05/2007.

74 HÉRITIER, Françoise, Masculino/Femenino. El pensamiento de la diferencia, T. I, Ariel, Barcelona, 1996.

75 HÉRITIER, Françoise, Masculino/Femenino. Disolver la jerarquía, T. II, Fondo de Cultura Económica, Buenos Aires, 2007, p. 11. 
En cierto sentido, Héritier distingue a las mujeres de lo femenino, planteándose la valorización de lo femenino inscripto en situaciones históricas particulares. Esboza interrogantes fecundos que al no ser de aplicación universal, particularmente caben en las formulaciones dieciochescas acerca de las mujeres. ¿La diferencia biológica es suficiente para establecer y no justificar una dominación masculina? ¿Por qué razones se desarrollan sistemas de pensamiento que valorizan lo masculino y desvalorizan lo femenino? ¿Por qué la jerarquía, signo de la desigualdad se instaura en pares binarios opuestos que deberían tener el mismo valor? ¿Basta referirse a la explicación naturalista y funcionalista que subraya la vulnerabilidad del cuerpo femenino, la imperfección de la naturaleza femenina que incluye la debilidad física?

A través del recorrido histórico que incluye no sólo el pensamiento de Aristóteles sino también la tradición judeocristiana en cuanto a las mujeres, en la referencia a hechos etnográficos, la antropóloga da cuenta del encorsetamiento femenino en las tareas domésticas ligadas a la reproducción y al mantenimiento del grupo sujetándolas en la ignorancia. También Héritier señala la ilusión esencialista, aquella que nos retrotrae a una naturaleza o "esencia" femenina imperfecta que justificaría la sumisión del género femenino. En ese sentido, la desigualdad femenina/masculina se instaura gracias a una simbolización fundadora del orden social y de las discrepancias mentales que aún siguen vigentes en ciertos núcleos sociales contemporáneos. Igualmente, Héritier hace hincapié en la valorización sistemática que se ha realizado de lo masculino desvalorizando los roles sociales de las mujeres dependientes de preguntas metafísicas y de construcciones mentales que terminan por crear sistemas de representación duraderos.

Pierre Bourdieu ${ }^{76}$ alude a las argumentaciones kantianas en torno a las mujeres, señalando que el principio de sus disposiciones afectivas radica en el estatuto asignado a la mujer en la división del trabajo de dominación y que Kant describió en un lenguaje falsamente contestatario, en el de una moral teórica disfrazada en ciencia de las costumbres. Cita a Kant:

Las mujeres -dijo Kant- ya no pueden defender personalmente sus derechos y sus asuntos civiles de la misma manera que no les corresponde hacer la guerra; sólo pueden hacerlo a través de un representante. ${ }^{77}$

En relación con esta cita, Bourdieu expresa que la renuncia y la docilidad que Kant imputa a la naturaleza femenina se inscriben en lo más profundo de las disposiciones constitutivas del habitus. Agrega que "La dominación masculina encuentra uno de sus mayores aliados en el desconocimiento que favorece la aplicación al dominador de categorías de pensamiento engendradas en la relación misma de dominación, libido dominantis (deseo

76 Si bien en la Dominación masculina, Bourdieu centra su análisis etnográfico de la sociedad calibeña, ofrece instrumentos reflexivos eficaces para una lectura de la dominación masculina en términos no restringidos a dicha sociedad (BOURDIEU, Pierre, La dominación masculina, Anagrama, Barcelona, 2000).

77 Ídem, p. 101. 
del dominador) que implica la renuncia a ejercer en primera persona la libido dominandi (deseo de dominar)" ${ }^{78}$ Bourdieu insiste en abordar el problema de las diferencias entre ambos sexos, con relación al racconto histórico y sociológico del dominio masculino, afirmando que está suficientemente asegurado como para no requerir justificación alguna. El efecto de la dominación simbólica se produce a través de los esquemas de percepción, de apreciación y de acción que constituyen los hábitos.

Además, el sociólogo francés profundiza en el efecto de la dominación simbólica que se produce a través de los esquemas de percepción y de apreciación sexuantes aplicados al cuerpo en su facticidad biológica. Advierte que la violencia simbólica se cristaliza a través de la adhesión naturalizada del dominado ante el dominador, al poner en práctica esquemas de percepción y de percibirse con las categorías otorgadas por otros, en este caso, por otros varones. Sin embargo, una lectura contemporánea acerca de las mujeres según la óptica kantiana no implica una deshistorización de sus núcleos problemáticos que hoy pueden ser leídos enmarcados en visiones naturalistas, esencialistas y androcéntricas, contribuyendo a la construcción social de subjetividades sobrecargadas de determinaciones sexistas.

Ciertamente, no se desconoce la problemática de la representación de la dominación masculina sobre el género humano, ni tampoco es tema de debate ni discusión en este trabajo, asumiendo que abundantes referentes teóricos y empíricos dan cuenta de la problemática mencionada. Dadas las características de este escrito, sólo nos interesa profundizar en algunas huellas conceptuales de la dominación masculina relacionada con las mujeres. En este sentido, desde una perspectiva histórica y sin perder de vista las culturas diferentes, Héritier sostiene que un sistema conceptual solapado que encontramos en sistemas simbólicos, adaptado a cada sociedad y a cada época se encuentra ya en Aristóteles, quien habilita sistemas simbólicos anteriores y los adapta a su tiempo no considerando a las mujeres más que materia: la forma y la vida humana son otorgadas al embrión por el pneuma espermático/hallado en el semen. ${ }^{79}$

Bourdieu afirma que el cuerpo biológico socialmente forjado es así un cuerpo politizado bajo los principios fundamentales de la visión del mundo androcéntrico, principios que son naturalizados bajo la forma de posiciones y disposiciones elementales del cuerpo percibidas como expresiones naturales de tendencias naturales (por ejemplo, la docilidad propia de las mujeres). Por estos motivos, argumenta que la educación básica es fundamentalmente política tendiendo a inculcar formas de mantener el cuerpo en su conjunto con notas sexualmente diferenciadas que expresan las oposiciones fundamentales de la visión del mundo. Sin embargo, la construcción intelectual y lógica que otorga a cada uno de los sexos posiciones indiscutiblemente opuestas, y categorías binarias asociadas a lo masculino: el heroísmo, agresividad, en oposición a las categorías femeninas hermanadas con la

79 HÉRITIER, Françoise, Masculino/Femenino. Disolver..., Op. Cit, p. 70-71.

\section{8}


suavidad, la pasividad, la sumisión, etc., estarían agrupadas en un sistema de categorización y en una "naturaleza" cuyo sistema de representación les otorga un grado de legitimidad.

\section{VI. ¿Mujer bella/Mujer bestia?}

Héritier nos acerca a la vertiente dual femenina citando a Yannicke Ripa, quien demuestra las características privativas de los campos de acción masculinos, jaqueadas durante la Guerra Civil Española: "Las rojas se pierden en una bestialidad que las convierte en hembras y no en víctimas. Ellas son hienas, feroces, y su violencia es percibida por los franquistas como una erotización sádica". ${ }^{80}$ En este registro, la "roja miliciana" se opone a la madre dolorosa franquista. Luego, en otro tono argumental, agrega que no hay que sorprenderse de que haya habido mujeres kapo en los campos nazis, ni de que actualmente las mujeres israelíes de extrema derecha reivindiquen el nombre de kapowatch que designa al grupo de mujeres que vigilan el accionar de mujeres israelíes de izquierda. ${ }^{81}$

Sin duda, ni hombres ni mujeres poseen un modelo normativo de género que prioriza la exclusividad de la violencia ni los valores belicosos como característica sexual natural. Múltiples factores inciden para que las pulsiones infantiles, las conductas y los deseos sean orientados disimilarmente según los sexos, generando categorías de percepción y pensamientos fuertemente marcados por patrones sexistas cargados de presuposiciones y prejuicios.

Héritier señala que la dominación masculina, en el sentido clásico del término, ha estado representada por las mujeres confinadas en el hogar limitadas a la gestión de lo biológico. Y para que esa esencia arcaica cambie radicalmente, las mujeres deben acceder a ese estatus de derecho que es el de la persona autónoma. ${ }^{82}$ En ese sentido, el estatuto de reproductoras impuesto a las mujeres resulta una palanca privilegiada de la dominación. Frente a ello, y en pos de lograr la autonomía, subraya la necesidad de otorgar a las mujeres el derecho a disponer del cuerpo propio, a reivindicar la paridad política, la igualdad en el acceso a la enseñanza, la igualdad profesional, salarial y de promoción laboral, el respeto por sus pensamientos y sus costumbres, la distribución de tareas, etc. ${ }^{83}$ como primer paso a dar por las mujeres para lograr el estatuto de sujetos autónomos. Sin embargo, la voluntad de igualitarismo no soslaya la existencia de la diferencia sexuada sino que marca, al reconocerla, la posibilidad de intercambio, complementariedad, restitución del equilibrio intelectual y simbólico de las categorías constitutivas de lo social que no reproduzca un sistema de desigualdades. Si bien la diferencia es innegable no implica o debería implicar como co-

80 Ídem, p. 77

81 Ídem, p. 87

82 Ídem, p. 129

83 Ídem, p. 26. 
rolario obligatorio la terminante desigualdad jerarquizada ${ }^{84}$ convirtiendo a las mujeres en una categoría subordinada y doméstica sujeta a la voluntad de lo masculino.

Es sabido que los valores de universalismo democrático implican la igualdad en la capacidad mutua y recíproca de representación de ambos sexos. No obstante, desde la concepción democrática griega hasta la actualidad, la efectiva discordancia entre el ideal democrático de la igualdad representativa electiva de todos los sujetos confronta con las prácticas discursivas que otorgan el estatus de representatividad pública a las mujeres y el ser reconocidas teniendo no sólo derechos privados sino también públicos. Héritier sostiene que históricamente, desde la puesta en marcha de la idea de democracia, "Las mujeres fueron apartadas de este triple nivel de estatus filosófico de individuo y de sujeto político de derecho por una interpretación que considera en suma que el carácter humano del individuo portador de derechos es reductible y puede superponerse a la virilidad, y que todas las capacidades de representación deben recaer ipso facto sólo en las manos de los hombres aptos, como hombres y como jefes de familia, para tratar los asuntos colectivos de la polis". ${ }^{85}$

Ese modelo arcaico de diferencia entre los sexos produce efectos profundos no sólo en un nivel conceptual sino en la realidad de las situaciones concretas no factibles de ser analizadas en este trabajo. A pesar de ello, no podemos dejar de reconocer que el universalismo democrático, siguiendo a la misma autora, subsume la desigualdad trascendental entre los sexos. El pensamiento es producto de su tiempo, de una visión cultural construida que prohíja la pertinencia de las oposiciones dualistas que ya hemos mencionado en párrafos anteriores Cabe reflexionar entonces acerca del discurso kantiano cuando explicita que sólo el hombre, lo viril, es la medida de lo universal. La admiración por la potencia viril y el confinamiento de las mujeres al rol de tareas repetitivas, obediencia debida a los hombres, alejamiento de las áreas del saber, son todas medidas que implican una denigración.

Lejos de agotarse en planteos dieciochescos, el estatuto de la ley-el marco dentro del cual se ha montado la cultura contemporánea-, ha creado sujetos e instituciones diferenciales para asegurarse una conservación de la dominación que aún no ha sido totalmente sustituida. El postulado jurídico de la igualdad y la división social de los sexos siguen debatiéndose en las filosofías de la descentralización y sujeción del sujeto, del sujet-assujet. Desde una mirada contemporánea al tratamiento discursivo dado a las mujeres por los autores estudiados, no sólo nos preocupó señalar las racionalizaciones justificativas elaboradas y la distinción de roles socialmente distribuidos, sino hemos pretendido avanzar en las asimétricas representaciones y en la particular torsión de las relaciones entre los sexos.

Coincidimos plenamente con lo expuesto por distintos autores acerca del sexismo ${ }^{86}, \mathrm{y}$

84 Ídem, p. 217.

85 Ídem, p. 229.

86 El sexismo, en tanto práctica e ideología que desvaloriza a las mujeres en relación con los hombres considerándolas como consecuencia de un orden natural. Ver: MICHEL, Andrée, Hacia una 
particularmente por Bourdieu, al plantear que el sexismo opera como un esencialismo al igual que el racismo, étnico o clasista, buscando atribuir diferencias sociales históricamente construidas a una naturaleza biológica que funciona como una esencia factible de deducir de modo implacable de todos los actos existenciales.

\section{Reflexiones finales}

Saberes incompletos y custodiados o la Ilustración tamizada

En nuestro viaje imaginario hemos documentado el discurso kantiano, lector de Rousseau, en cuanto a las conceptualizaciones y mensajes para referirse a la condición de lo femenino y a lo deseable acerca de la posición de las mujeres en su medio histórico social en términos de normas concretas. Para ello, apelamos a desgranar las cualidades y atributos que debían cumplimentar las mujeres para ser aceptadas y valoradas más allá de la escena doméstica. En este sentido, ilustramos los valores instituidos socialmente para acentuar el lugar otorgado a las mujeres. Hemos dado visibilidad a las concepciones dieciochescas-en este caso compartidas por Rousseau y Kant-, en cuanto a las capacidades de las mujeres centradas en patrones de dependencia, receptividad, predominio de una razón práctica que obstruía su capacidad de abstracción y las consecuentes limitaciones en las oportunidades de desarrollo de las mismas. Hemos pincelado ciertas caracterizaciones que visibilizan en la concepción ilustrada de las mujeres, un modelo teórico diseñado sobre el concepto de igualdad que se contradijo en la práctica discursiva al reducir lo universal al sujeto varón.

Desde una perspectiva analítica contemporánea, acordamos con Vandewalle al afirmar que un examen de la concepción kantiana de la educación requiere una investigación del conjunto del pensamiento crítico y no un comentario de los textos pedagógicos, ${ }^{87}$ realizando una sutil disección de la "circulación" del concepto de educación en la totalidad del corpus kantiano en los ámbitos de la gnoseología, filosofía moral, estética, antropología y filosofía de la historia y filosofía crítica, en relación con una educación auténticamente ilustrada" ${ }^{88}$ El aprender a pensar por uno mismo en lugar de aprender pensamientos constituye un desiderátum impostergable, poniendo en movimiento una concepción crítica de la pedagogía centrada en un aprendizaje de la autonomía y de la libertad y registrando, a su vez, las innovaciones conceptuales del pensamiento crítico.

En otro orden de ideas, destacamos la valorización que Kant otorga al pasaje de la animalidad a la humanidad ${ }^{89}$ y el rol protagónico y central que asume la educación en el mismo,

superación del sexismo en los libros infantiles y escolares, UNESCO, Barcelona, 1987.

87 VANDEWALLE, Bernard, Kant. Educación..., Op. Cit., p. 8.

88 Ídem, p. 9.

89 Los desarrollos pedagógicos kantianos compilados en su Pedagogía y/o Lecciones de Pedagogía dan muestra acabada de estas afirmaciones. 
producto del dispositivo propio de la segunda mitad del siglo XIX. Asimismo, subrayamos en su planteo, la importancia asignada a la educación pública sobre la privada. Sin embargo, acordando con Vandewalle consideramos que "pensar una educación auténticamente ilustrada es enfrentarse a una serie de círculos" ${ }^{90}$ Círculos, esferas, triángulos y otras figuras geométricas que nos muestran facetas kantianas en anagrama de interrogación.

Pero, sin incurrir en anacronismos, consideramos que las posibles lecturas contemporáneas de los discursos dieciochescos acerca de las mujeres estudiados en este trabajo, nos han mostrado cómo la arquitectura discursiva de los poderes de los cuerpos femeninos y masculinos, de sus potencialidades, carencias y apetencias, ha conducido a una construcción social naturalizada legitimando una relación de dominación al inscribirla en patrones biológicos predeterminados. De este modo, el determinismo biológico observado, no sólo en las categorías de "sexo" y/o de "diferencia sexual", arrastra los resabios preiluministas dando cuenta de la entonces vigente ideología con relación al rol de las mujeres en el retoño de las Luces. Por lo tanto, la igualdad y desigualdades señaladas operaron como algo ontológicamente dado y construidas por la aplicación de pautas educacionales diferenciales según los sexos.

De acuerdo con los análisis precedentes, la caracterización de las mujeres como seres biológicos, emocionales y socialmente diferentes de los hombres, dotadas de derechos y de oportunidades diferentes para el acceso a los conocimientos, no resulta inadecuada para explicar las desiguales relaciones entretejidas en la arquitectura del poder del discurso estudiado. Tanto Héritier como Bourdieu han aportado sus análisis contundentes iluminando los funcionamientos asimétricos de las fuentes discursivas organizadoras del proceso de poder masculino.

Acorde con la perspectiva dieciochesca la constitución del sujeto social, lejos de un proceso de comprensión, apunta a desglosar la subjetividad y los saberes femeninos y masculinos en términos de desdibujamiento de los lazos igualitarios. Hemos observado que las mujeres, en los discursos analizados, no participan de los saberes codificados de las ciencias iluministas, ni del postulado jurídico de la igualdad, ni menos aún de la universalidad de la ley. Además, subrayamos cómo la preparación para la actividad teórica y el desarrollo del pensamiento riguroso, más allá de la declamada y alentada universalidad de los saberes, aún quedaba reservada al coto varonil.

Recibido: 09/04/2012

Aceptado: 12/06/2012 